University of Montana

ScholarWorks at University of Montana

10-1992

\title{
Avian Forelimb Muscles and Nonsteady Flight: Can Birds Fly Without Using the Muscles in their Wings?
}

Kenneth P. Dial

University of Montana - Missoula, kdial@mso.umt.edu

Follow this and additional works at: https://scholarworks.umt.edu/biosci_pubs

Part of the Biology Commons

Let us know how access to this document benefits you.

\section{Recommended Citation}

Dial, Kenneth P., "Avian Forelimb Muscles and Nonsteady Flight: Can Birds Fly Without Using the Muscles in their Wings?" (1992). Biological Sciences Faculty Publications. 215.

https://scholarworks.umt.edu/biosci_pubs/215

This Article is brought to you for free and open access by the Biological Sciences at ScholarWorks at University of Montana. It has been accepted for inclusion in Biological Sciences Faculty Publications by an authorized administrator of ScholarWorks at University of Montana. For more information, please contact scholarworks@mso.umt.edu. 


\title{
AVIAN FORELIMB MUSCLES AND NONSTEADY FLIGHT: CAN BIRDS FLY WITHOUT USING THE MUSCLES IN THEIR WINGS?
}

\author{
KENNETH P. DiAL \\ Division of Biological Sciences, University of Montana, Missoula, Montana 59812, USA
}

\begin{abstract}
Intensity patterns of electromyographic (EMG) signals from selected muscles of the wing were studied during different modes of flight in trained Rock doves (Columba livia). Shoulder muscles exhibited a stereotypic pattern producing maximal EMG intensity during the deceleration phases of the upstroke and the downstroke, whereas the muscles of the brachium and antebrachium acted primarily as joint stabilizers during level flapping flight. During nonsteady flight (e.g. takeoff, landing, vertical ascending flight), the distal forelimb muscles exhibited maximal EMG intensity; their primary function appears to be associated with changing the camber and planform of the wing during rapid oscillation. During steady flight, an automatic linkage system consisting of forelimb skeletal elements and ligamentous attachments is thought to permit proper excursion of the wing as a result of forces generated solely by proximal muscles of the wing. To test this hypothesis, the medianoulnaris and radialis nerves were cut in five animals, thus eliminating the contribution of the forearm muscles, and flight tests were performed. Even though forearm muscles were incapable of contracting, the birds were capable of sustained level flapping flight. They were unable to take off independently or perform controlled landings. Received 3 October 1991, accepted 29 March 1992.
\end{abstract}

DESPITE THE large number of bird species, the wide range of wing shapes (Savile 1957), and variation in flight styles or wing-beat gaits (Rayner 1988), natural selection has acted to retain the basic musculoskeletal design of the avian forelimb. Few data exist on the functional relationship between a species' flying capabilities and its forelimb musculoskeletal architecture. Previous studies of the musculoskeletal system document structural variation, but few studies (see Brown 1948, Fisher 1946, Sy 1936) address the functional aspects of forelimb components.

Compared with terrestrial locomotion, flying is metabolically efficient per unit distance travelled, but energetically expensive per unit time (Tucker 1968, Schmidt-Nielsen 1984); this is due to the muscular demands associated with generating lift using a rapidly oscillating appendage. Consequently, the musculoskeletal apparatus of the avian forelimb should be subject to considerable selective pressures. One way to minimize the moment of inertia of a rapidly moving appendage is to distribute the mass closer to the pivot (Hildebrand 1988). This phenomenon is evident among birds as the bulk of the wing's mass is positioned proximally. In many cases, the distal one-half of the wing consists almost entirely of feathers.

If natural selection acts to reduce energetically costly distal mass, then why are brachial and antebrachial muscles within the avian wing retained? Are these muscles necessary to extend and flex the wing during each and every wingbeat and/or do they make subtle changes to the shape of the wing during different modes of flight? In some avian species the forearm musculature is proportionally reduced (e.g. albatrosses) and in others it is relatively robust (e.g. pigeons, gallinaceous birds, and hummingbirds). In order to understand the contribution of forelimb muscles to wing kinematics, it would be helpful to determine when they are active during normal locomotion.

Bock (1974) and Raikow (1985) noted the paucity of studies in avian functional anatomy that incorporate the latest techniques to measure neuromuscular physiology and musculoskeletal biomechanics. Over the past several decades electromyography, coupled with high-speed photography, has proven to be an important tool for assessing in vivo muscle function (e.g. Gorniak and Gans 1980, Jenkins and Goslow 1983, Shaffer and Lauder 1985, Dial et al. 1987, 1988, 1991, Dial 1992). In this study, I focus on changes in the intensity of electromyographic signals (EMGs) during phases within the wingbeat cycle and among modes of flight from selected wing muscles in trained Rock Doves ( $\mathrm{Co}-$ lumba livia). Then, by eliminating the neural control (i.e. denervation) of certain muscle 
groups, I examine whether forelimb muscles are required for sustained flapping flight.

\section{MATERIALS AND METHODS}

Animals and training procedures.-I used 23 adult Rock Doves in the electromyographic experiments, five of which were used specifically for denervation experiments. All birds (body mass, $\bar{x}=326 \pm \mathrm{SD}$ of $19 \mathrm{~g}$ ) were captured from wild populations in Missoula County, Montana, housed in stainless-steel cages (1 $\mathrm{m}$ wide $\times 1 \mathrm{~m}$ deep $\times 1.5 \mathrm{~m}$ high), and maintained with commercial pigeon feed, vitamins, and water ad libitum.

Birds were trained to fly down a hallway $(50 \mathrm{~m}$ long $\times 3.1 \mathrm{~m}$ wide $\times 2.7 \mathrm{~m}$ high) and to land on a platform (1.3 m high). Takeoff was analyzed as the first five wing beats following an unassisted liftoff from the ground. Level flight was measured from five random wing beats during a $30-\mathrm{m}$ flight, where the animal flew level along the flyway. Landing was analyzed from the final five wing beats as the animal approached the landing platform. Vertical ascending flight was recorded as the bird flew to a perch positioned $2.5 \mathrm{~m}$ directly above the bird. To simulate experimental recording conditions, each bird was conditioned to fly carrying one end of a recording cable (enclosing 12 insulated and electrically shielded recording wires approximately $25 \mathrm{~m}$ long) secured to the animal's back and directed along the flank of the bird, permitting normal movement of the wings and tail.

Cinematography.-Each EMG recording sequence was filmed using a 16-mm, high-speed movie camera (LoCam, Red Lakes Laboratory) at 200 to 400 frames s $^{-1}$. An electrical pulse synchronized with each frame of film (Kodak 7250 Ektachrome) was used to reference wing position during flights of denervated and nondenervated birds. Lighting for the high-speed camera required 12 1,000-watt quartz lights (Tota-Light, T110, Lowel Company) positioned along the flyway. Films were analyzed using an L-W (model 224-S) film projector, and kinematic measurements were made using a ruler and protractor set against a projection screen. Flight velocity, body angle, and flight trajectory were determined from films taken in lateral view. Measurements of wing excursion and observations of deviations in wing movement between normal and denervated wings were made from films taken in anterior view.

Electromyography. - Electromyograms were obtained using procedures presented in Dial et al. (1988) and Dial (1992). Pigeons were anesthetized with intramuscular injections of ketamine $(25 \mathrm{mg} / \mathrm{kg})$ and xylazine $(2 \mathrm{mg} / \mathrm{kg}$ ). Several incisions $(10-15 \mathrm{~mm})$ were made on the skin located over the muscle(s) to be implanted and also where a back plug was secured. This connector plug (Microtech, FG-6) contained six fine-wire bipolar silver electrodes $(100 \mu \mathrm{m}$ diameter,
California Fine Wire, Chatsworth, California) and was sutured to the intervertebral ligaments between the scapulae. Electrodes were threaded subcutaneously from the back plug to the site of implantation by guiding them through a temporarily inserted polyethylene canula. Each electrode pair was implanted into a muscle using a 25-gauge hypodermic needle. To prevent electrodes from slipping out of the muscle, each electrode pair was sutured to surrounding fascia or, if necessary, to the muscle tissue at the electrode exit point. Following surgery the bird was fitted with a protective, cone-shaped collar and placed in a recovery cage supplied with food, water, and a heated pad. All electromyographic recordings were made the day following surgery.

Simultaneous signals from up to six muscles were amplified (gain $=500 \times$ to $2,000 \times$ using Grass P511J preamplifiers; filter settings $=100 \mathrm{high}$ pass and 300 low pass) and recorded on a Keithley DAS analog-todigital 12-bit computer (sampling rates $=2,040-3,000$ $\mathrm{Hz}$ per channel) and signals stored on a Zenith $386 \mathrm{SX}$ personal computer. Electromyographic data were analyzed by converting the digital data back into their analog form (using software developed by George V. Lauder [University of California at Irvine] and by Garr Updegraff [DataCrunch, San Clemente, California]) and displayed on a Tektronix 4109 graphics terminal. The intensity of each EMG was measured by dividing the rectified burst of activity for each wing beat into 5-millisecond(ms)-wide bins and calculating the product of the mean spike amplitude times the number of spikes for each bin; the results were displayed as intensity profiles under each raw EMG signal. Onset, offset, and total duration (0.3-ms accuracy) also were measured for each EMG signal with the pectoralis EMG onset as the reference for all muscles. EMGs and intensity profiles were plotted using a HewlettPackard 7470A plotter (100-points-per-inch resolution).

Electrode tip placement was verified by: (1) visual observation during surgical implantation; (2) electrical "back stimulation" (providing observation of muscle contraction); and (3) postmortem dissection. Data from electrodes that moved during recording were eliminated from analyses.

Denervation experiments. - Selected muscle groups of the wing (e.g. flexors of wrist) were incapacitated by sequentially cutting the medianoulnaris nerve (along proximal, dorsal brachium) and then the radialis nerve (near proximal, midventral brachium; Fig. 1). Birds were flown and electrode signals monitored prior to and following each denervation $(45 \mathrm{~min}$ after procedure and once each day for seven days following denervation). The bird was administered a local anesthetic (Lidocaine), and the medianoulnaris nerve and radialis nerve were approached through skin incisions prepared the previous day (i.e. same day electrodes were implanted). Nerves were severed (using microscissors) unilaterally (left side) in three birds 


\section{A}

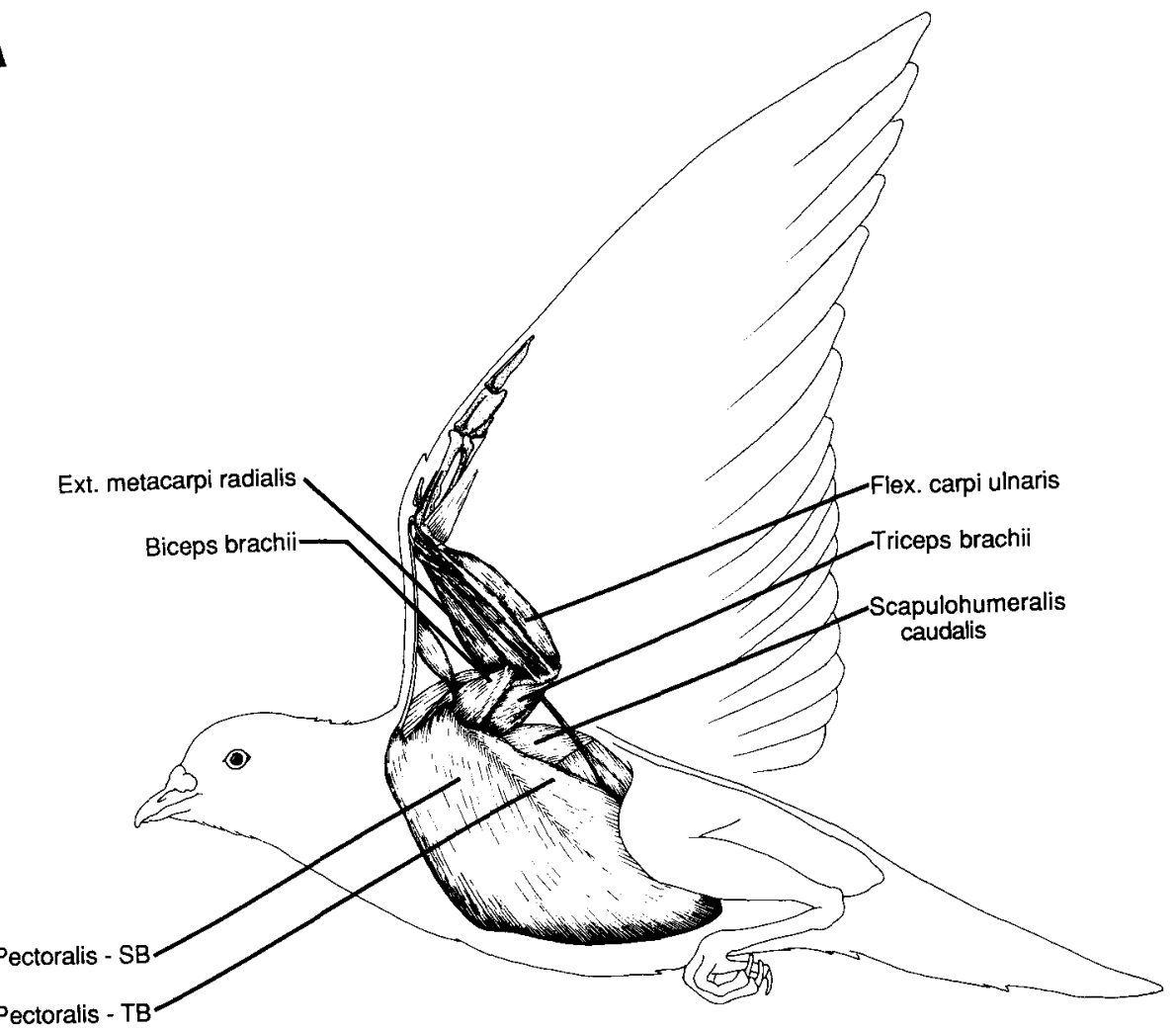

B
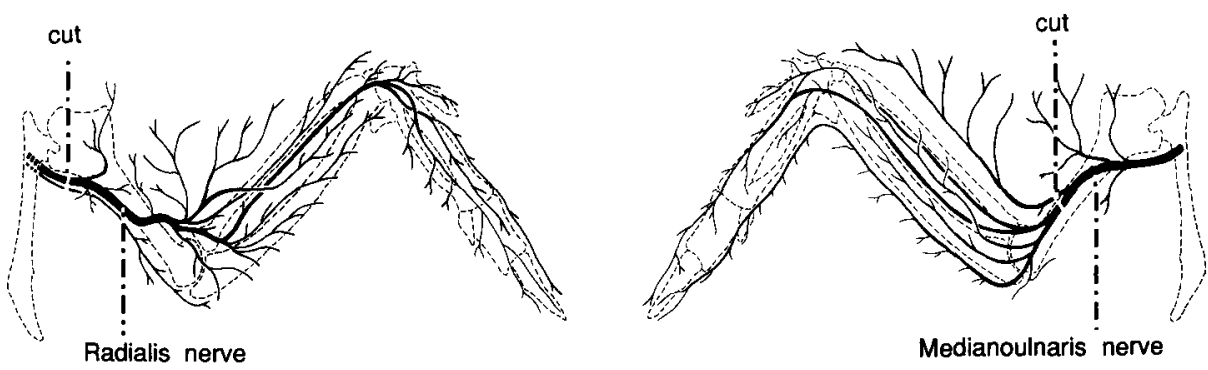

Fig. 1. (A) Musculature of flight apparatus of the Rock Dove. Supracoracoideus lies deep to pectoralis. (B) Nerves of wing (dorsal view on right, ventral view on left side) illustrating regions where nerve branches were cut (modified from Breazile and Yasuda 1979:fig. 5).

and bilaterally in two birds. Unilateral denervations permitted simultaneous comparison of kinematics of denervated and normal wings.

\section{RESULTS}

Muscle intensity.-The EMG intensity profiles from the three major shoulder muscles reveal that the neuromuscular input during the deceleration phases (end of both upstroke and downstroke) of each wing-beat cycle are periods of peak muscle activity (Fig. 2). In other words, during level flapping flight, the major downstroke muscle (pectoralis thoracicus) normally exhibited its greatest EMG intensity during the final one-third of the upstroke phase. The primary upstroke muscle (supracoracoideus) always exhibited its greatest activity at the end of the downstroke phase (Fig. 2). The scapulohumeralis caudalis, considered to be a 


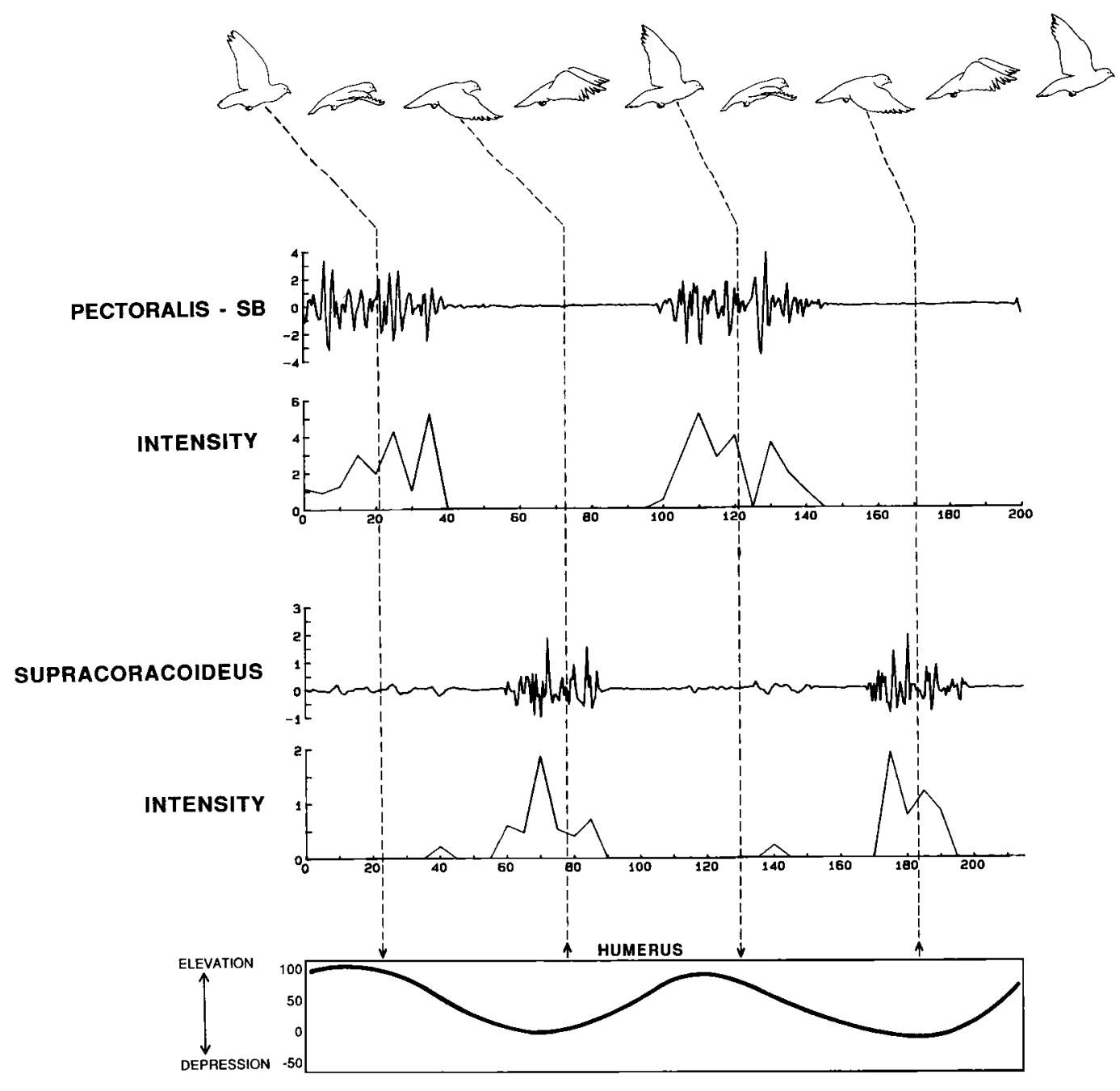

\section{SCAPULOHUMERALIS CAUDALIS}

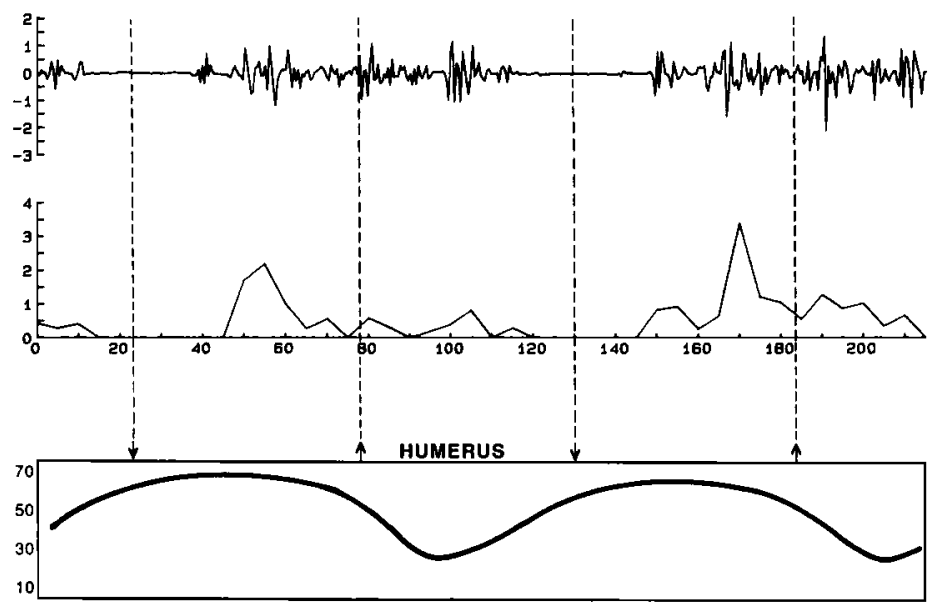

Fig. 2. Raw EMG activity $(\mathrm{mV})$ and intensity profiles ( $\mathrm{mV}$ multiplied by milliseconds, calculated for each 5 -ms bin within a wing beat; time in ms on $x$-axis) during two wing-beat cycles for three shoulder muscles of Rock Dove. Approximate angles (degrees) of excursion of humerus determined from movie film and manipulation of wing in hand. Estimated flight velocity was 7 to $8 \mathrm{~ms}^{-1}$. 


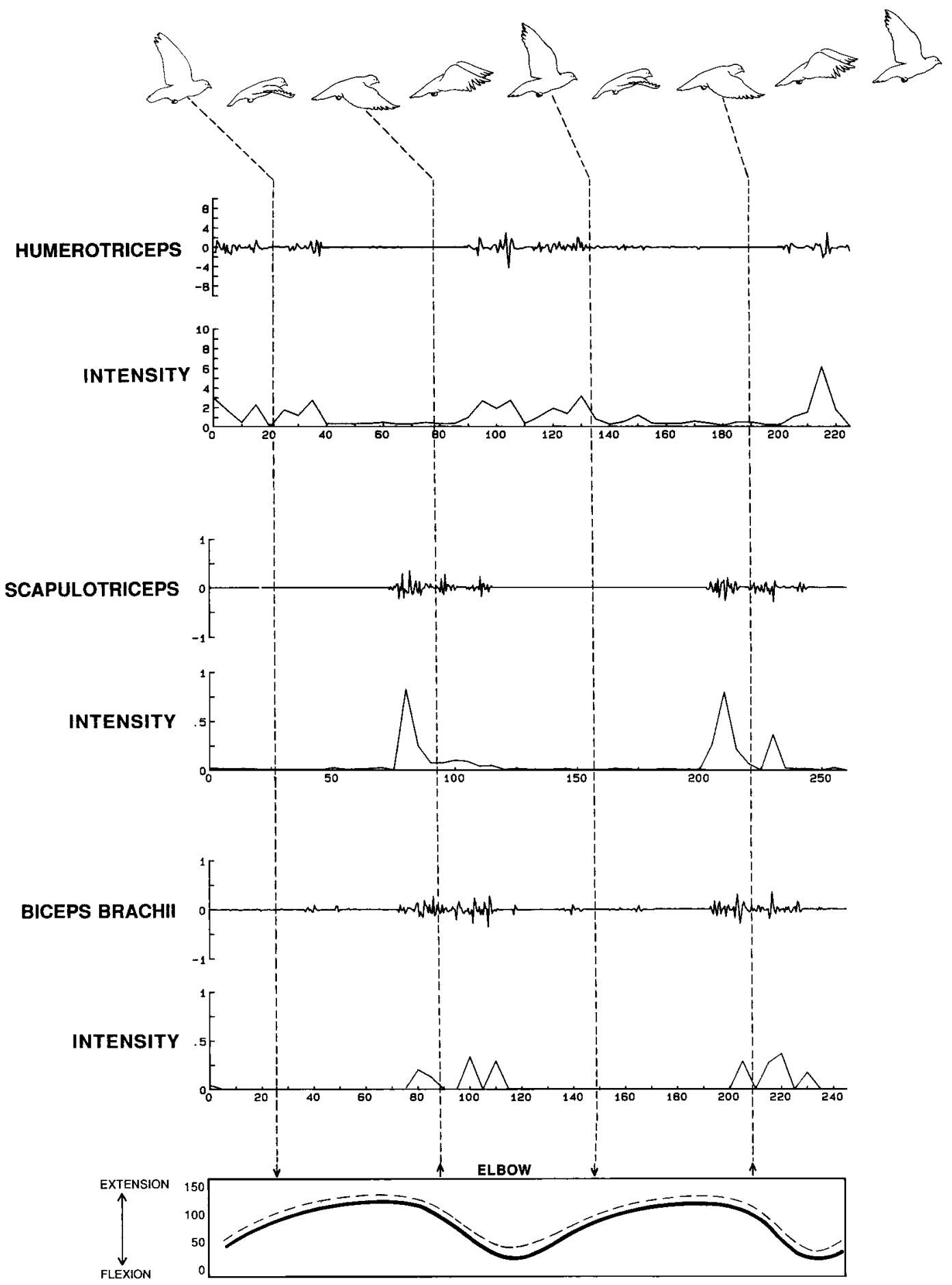

Fig. 3. Raw EMG activity ( $\mathrm{mV}$ ) and intensity profiles ( $\mathrm{mV}$ multiplied by milliseconds, calculated for each 5 -ms bin within a wing beat; time in ms on $x$-axis) during two wing-beat cycles for three brachial muscles of Rock Dove. Approximate angles (degrees) of excursion of humerus determined from movie film and manipulation of wing in hand. Estimated flight velocity was 7 to $8 \mathrm{~ms}^{-1}$. 


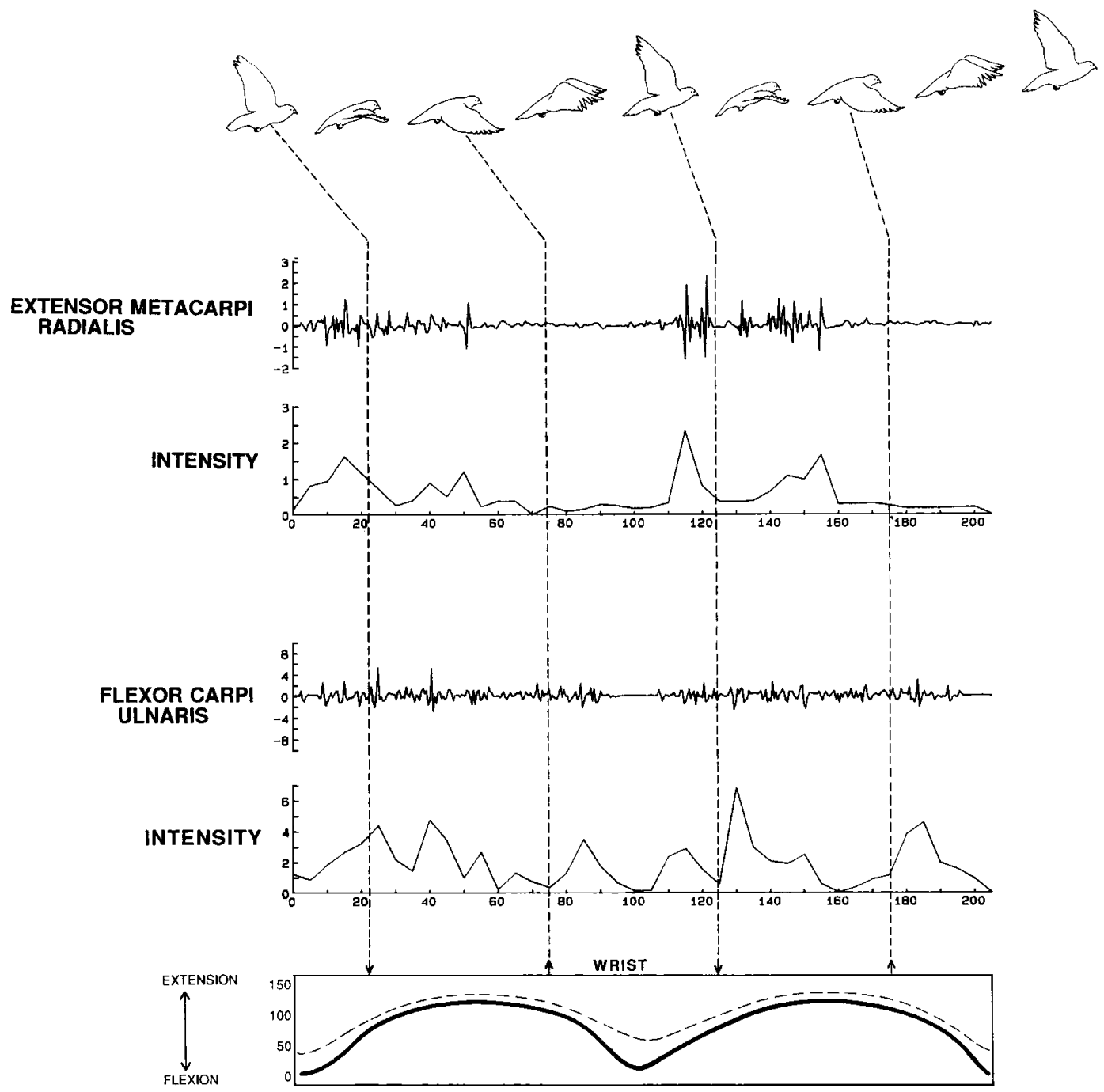

Fig. 4. Raw EMG activity $(\mathrm{mV})$ and intensity profiles $(\mathrm{mV} \times \mathrm{ms}$ calculated for each 5-ms bin within a wing beat; time in ms on $x$-axis) during two wing-beat cycles for two major antebrachial muscles of Rock Dove. Approximate angles (degrees) of excursion of humerus determined from movie film and manipulation of wing in hand. Estimated flight velocity was 7 to $8 \mathrm{~ms}^{-1}$.

major humeral retractor (Raikow 1985), exhibited its strongest activity during the second onehalf of the downstroke (Dial 1992). These data suggest that the greatest EMG intensity generated by the major shoulder muscles is associated with the period of active lengthening (i.e. when muscle is stretching) in preparation for the subsequent shortening phase in order to generate greater forces of contraction (for discussion of this neuromuscular phenomenon, see Cavagna et al. 1965).

Moving distally along the wing, the humerotriceps was active during the final two-thirds of the upstroke and continued into the first onethird of the downstroke (Fig. 3). The biceps brachii was active during the upstroke-downstroke transition. Both muscles exhibited relatively uniform intensity when active during level flapping flight. The scapulotriceps was active throughout the upstroke-downstroke transition (wing turnaround) and exhibited its greatest activity during the final one-third of the downstroke. During level flapping flight, the scapulotriceps and the biceps brachii were consistently coactive (Fig. 3).

Antebrachial (forearm) muscles exhibited low- 


\section{LEVEL FLAPPING FLIGHT}

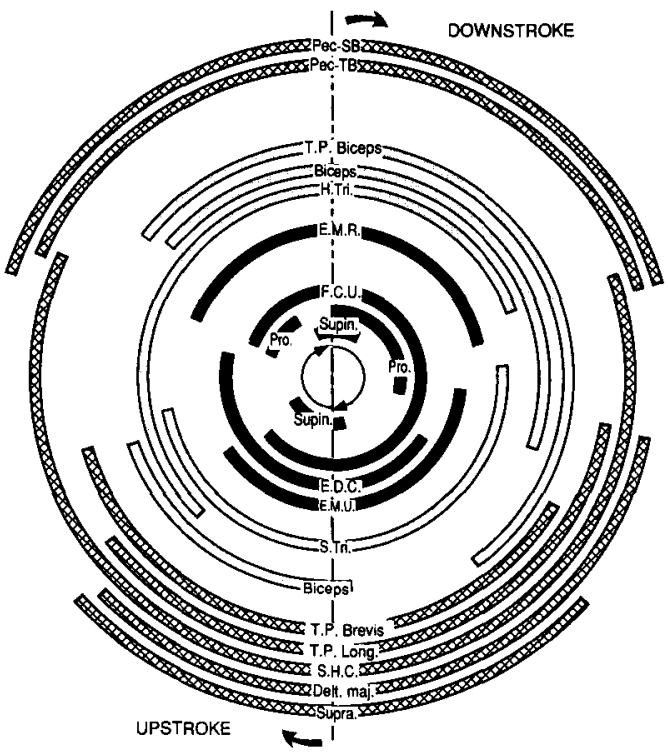

ASCENDING FLIGHT

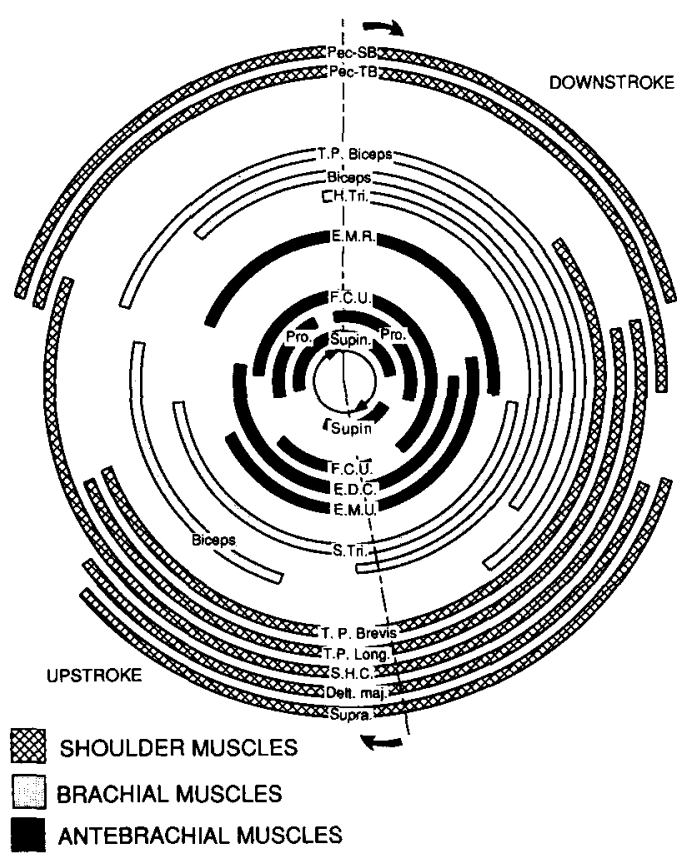

Fig. 5. Cycle of electromyographic activity in wing muscles of Rock Dove during level flapping flight (upper) and vertical ascending flight (lower). Dashed line at top of two circular diagrams (at $0^{\circ}$ ) identifies the point within wing-beat cycle when humerus is fully elevated (i.e. beginning of downstroke), and dashed line at bottom of each circular diagram (at $180^{\circ}$ ) identifies when humerus is fully depressed (i.e. beginning of upstroke). Note that onset and offset and variable-amplitude signals during level flight (Fig. 4). Two of the major antebrachial muscles, the extensor metacarpi radialis and the flexor carpi ulnaris, exhibited their greatest EMG activity during nonsteady flight when the wing dramatically changes its surface area from that of level flapping flight. As each bird established straight and level flight following takeoff, EMG activity from all antebrachial muscles greatly diminished. A survey of the EMG activity patterns for most of the antebrachial muscles is presented elsewhere (Dial 1992).

The durations of the upstroke phase and the downstroke phase within a wing-beat cycle differed between vertical and all other modes of flight. Downstroke and upstroke phases were of equal duration (i.e. each representing $50 \%$ of the wing-beat cycle) during level flapping flight, takeoff, and landing (wing-beat duration, $\bar{x}=$ $121 \pm \mathrm{SD}$ of $12 \mathrm{~ms}, 110 \pm 13 \mathrm{~ms}$, and $119 \pm 11$ ms, respectively; $n=50$ wing beats per flight mode). During vertical ascending flight, the downstroke accounted for $43 \%$ and the upstroke $57 \%$ of the wing-beat cycle (wing-beat duration, $\bar{x}=104 \pm 7 \mathrm{~ms}, n=50$ wing beats; Fig. 5).

The relative timing of the EMG signals (e.g. onset and offset times) changed little during different modes of flight (Fig. 5), whereas the EMG intensity changed significantly. This was most obvious for muscles distal to the shoulder. For example, the duration and relative offset times of the extensor metacarpi radialis exhibited minor changes among the different modes of flight, whereas their EMG intensity changed 3.5-fold from level flapping flight to takeoff.

times for each muscle do not change dramatically between flight modes, and that downstroke represents $7 \%$ less of total cycle in ascending than in level flapping flight. Abbreviations: Pec-SB and Pec-TB = pectoralis major pars thoracicus sternobrachialis and thoracobrachialis, respectively; T.P. Biceps $=$ tensor propatagialis pars biceps; Biceps $=$ biceps brachii; $\mathrm{H}$. Tri. = humerotriceps; E.M.R. = extensor metacarpi radialis; F.C.U. = flexor carpi ulnaris; Pro. = pronator superficialis; Supn. = supinator; F.C.U. = flexor carpi ulnaris; E.D.C. = extensor digitorum carpi; E.M.U. = extensor metacarpi ulnaris; $\mathrm{S}$. Tri. = scapulotriceps; T.P. Brev. = tensor propatagialis pars brevis; T.P. Long. = tensor propatagialis pars longa; S.H.C. = scapulohumeralis pars caudalis; Delt. maj. = deltoideus major; and Supra. = supracoracoideus. Adapted from Dial (1992). 
Denervation experiments.-An example of the EMG activity from a pre-denervated pigeon during level flapping flight from three muscles (the major wing depressor [pectoralis], a wrist extensor [extensor metacarpi radialis], and a wrist flexor [flexor carpi ulnaris]) is provided in Figure 6A. Subsequent to the denervation of the medianoulnaris, the animal was unable to activate its wrist flexors or pronators (Fig. 6B). This is evident by the flat-line signal for the EMG electrode residing in the flexor carpi ulnaris. The animal struggled to take off, but was able to sustain level flapping flight. In this condition, the bird struggled to alight on the $0.3-\mathrm{m}^{2}$ landing platform. When both the medianoulnaris and radialis nerves were severed (Fig. 6C), incapacitating all of the wing muscles distal to the shoulder (except the biceps and brachialis [innervated by musculocutaneous nerve] and triceps [two heads of which are innervated by more proximal branches of radial nerve]), the animal was unable to take off. However, after being launched (by hand) into the air, the bird was able to fly the entire length of the 50-m flyway. With both the medianoulnaris and radialis nerves cut, all birds were incapable of performing a controlled landing. The bird either gradually descended from level flight prior to reaching the platform, whereupon it landed on its belly and slid along the floor for a distance of 3 to $5 \mathrm{~m}$, or the bird descended vertically, in an uncontrolled manner, to the floor.

Inspection of movie films of unilaterally denervated birds showed that the denervated wing was unable to fully extend during nonsteady flight. However, during level flapping flight, the normal and denervated wings moved symmetrically, with no discernable difference in wing kinematics observed from the films. Animals that were denervated bilaterally exhibited the same flight capabilities as the unilaterally denervated animals.

\section{Discussion}

A biomechanical linkage system within the forelimb, identified over 100 years ago, apparently provides the necessary control to automatically extend and flex the wing using input solely from the shoulder musculature. Headley (1895) demonstrated, using a dead bird, that when the elbow joint is passively extended, an automatic extension of the wrist and the spread- ing of the feathers could be achieved (for further discussion, see Sy 1936, Hildebrand 1988). Fisher (1957) found that, when the tendons of the wrist flexors and extensors were cut in a pigeon, the bird was capable of flight. However, Fisher did not specify anything about the type of flight the birds achieved (i.e. takeoff, ascending, descending, landing) but only that two birds could fly after recovery from operation.

It appears that the skeletal linkage system within the avian forearm (comprising a collapsible parallelogram) is particularly important during level flapping flight because it permits a coordinated extension and alignment of the wing. I propose that the evolutionary retention of the forearm muscles is a consequence of the fact that those muscles are needed for modification of the shape of the wing during periods of nonsteady flight. I propose further that forelimb muscles in most birds are not essential for normal extension and flexion of the wing during each and every wing beat. Even though all forelimb muscles generated low-level electromyographic signals during short-range flights $(30-50 \mathrm{~m})$ when the birds were carrying a section of the recording cable, these muscles are primarily involved in controlling the wing during nonsteady flight (e.g. takeoff and landing). The forces required to modify the shape of a rapidly moving wing during nonsteady flight are expected to be substantial, and the degree of forearm muscle development may be correlated with the amount of nonsteady flight each species routinely performs.

The significance of the change of wing span during each wing beat in steady flight has been discussed by Spedding (1987). He suggests that the observed forelimb kinematics enables the bird to maintain a bound vortex of constant circulation on its wing, thus minimizing the amount of energy wasted in shedding vortices into the wake. Spedding (1987) and Pennycuick (1988) maintained that cyclic changes of wing span are a key adaptation for economical cruising flight in birds, but this phenomenon apparently is absent in bats.

My results suggest that significant metabolic savings may be enjoyed by birds that undertake frequent and prolonged periods of level flapping flight. If the muscle activity is reduced or completely shut down, then the metabolic costs required to operate the avian locomotor apparatus would be reduced. Perhaps birds use a physiological strategy similar to that employed 

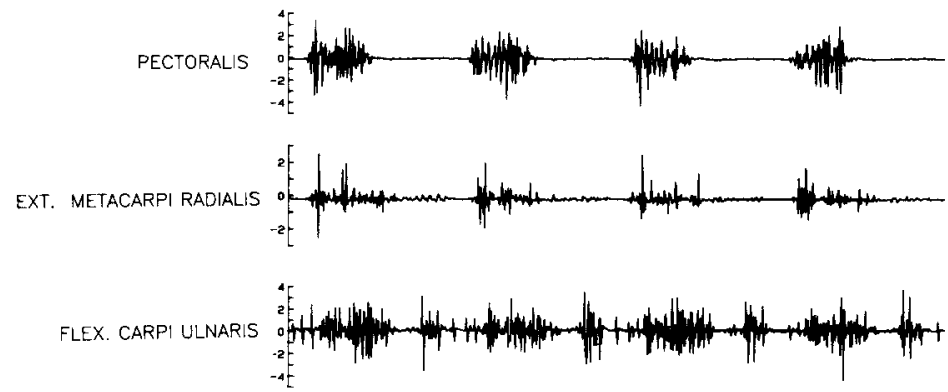

B

PECTORALIS

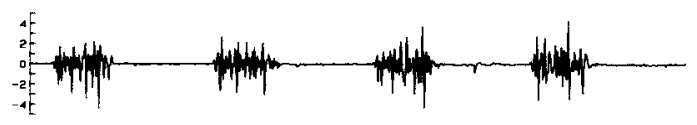

EXT. METACARP I RADIALIS

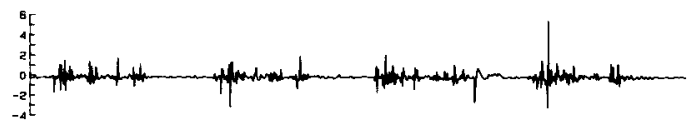

FLEX. CARPI ULNAR!S

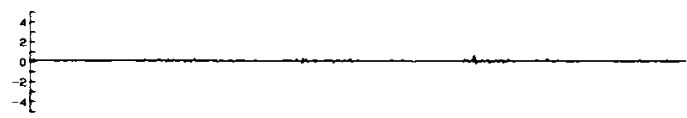

C

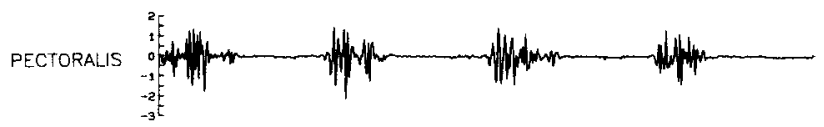

EXT. METACARPI RADIALIS

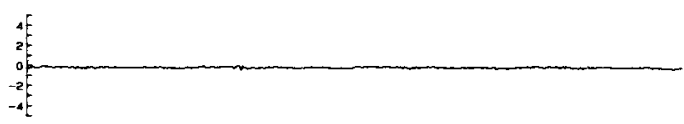

FLEX. CARPI ULNARIS

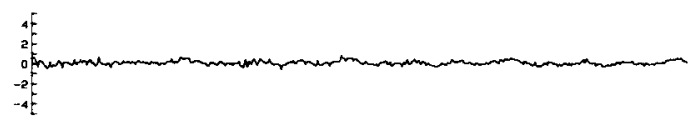

Fig. 6. Electromyographic signals of the primary downstroke muscle (pectoralis), a wrist extensor (extensor metacarpi radialis), and a wrist flexor (flexor carpi ulnaris) during four wing-beat cycles. (A) EMG signals recorded from normal Rock Dove prior to denervation. (B) EMG signals recorded following denervation of medianoulnaris nerve. Note that flexors and pronators of wing are incapacitated (indicated by flat-line signal from flexor carpi ulnaris). (C) EMG signals recorded from Rock Dove during level flapping flight after both radialis and medianoulnaris nerves cut. Note that pectoralis is active, but extensors and flexors of wrist exhibit no EMG activity. Bird is capable of level flapping flight, but cannot take off or land in coordinated fashion. 


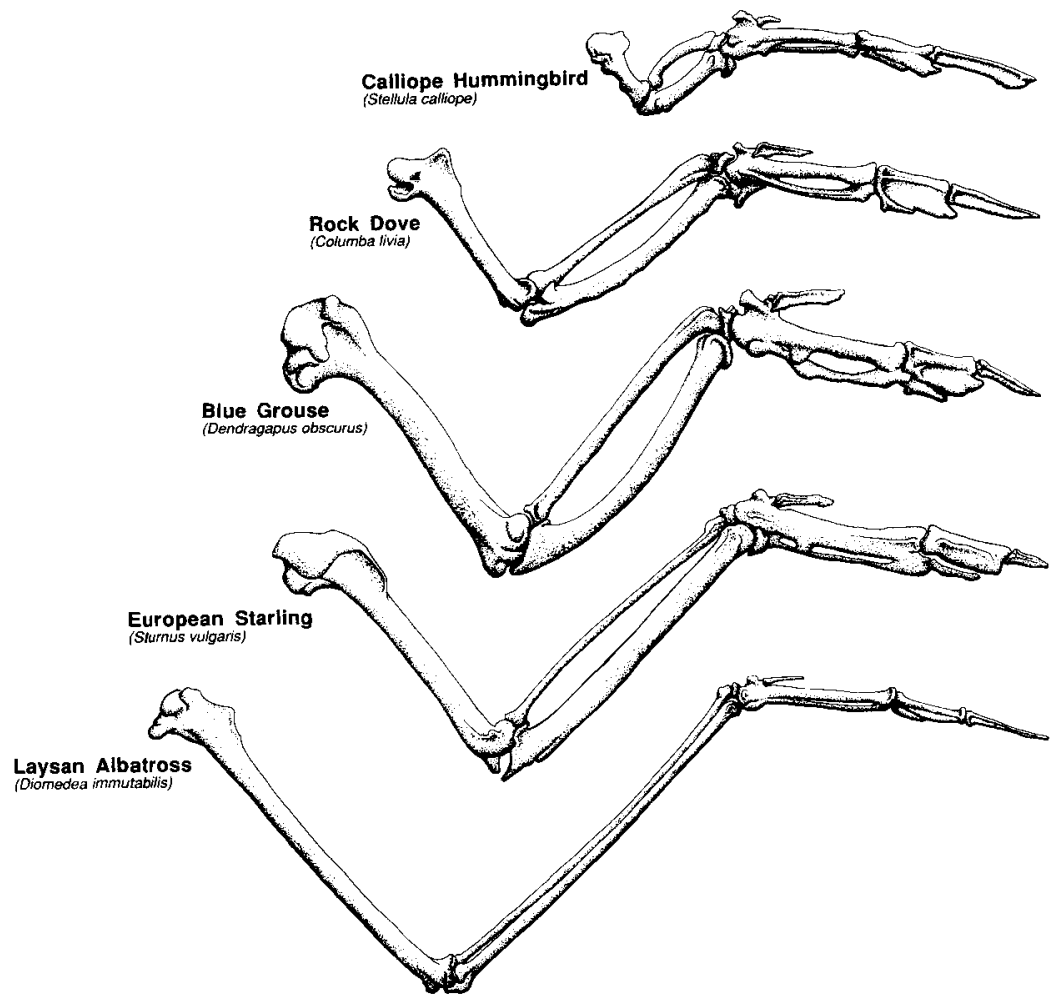

Fig. 7. Skeletal elements of forelimb in five species of birds scaled so that carpometacarpi of equal length. In birds that display large amount of nonsteady flight (e.g. Black-chinned Hummingbird, Rock Dove, and Wild Turkey), all possess robust skeletal elements, and ulna and radius bow away from each other. This indicates a significant amount of muscle mass associated with antebrachium. Species with no bowing of ulna and radius, such as the albatross, possess little forelimb musculature and are not coordinated in nonsteady flight. Most species, such as passerines, possess an intermediate condition with a modest mass of forelimb musculature.

by various marine mammals, which metabolically shut down the peripheral body parts during extended underwater dives (Irving et al. 1942, Scholander 1964). An interesting study would be to determine if birds restrict both the circulation and degree of muscle activity within the wing during steady flight and, thus, rely on their forelimb linkage system to control the wing movements at a fraction of the energetic cost.

The activity patterns of the scapulotriceps and biceps brachii suggest that these antagonists are acting as elbow-joint stabilizers during the final one-half of the downstroke and, therefore, do not appear to be responsible for actively extending or flexing the wrist during level flapping flight. Consistent with the brachial muscles, the activity of the antebrachial muscles suggests they also act to stabilize their common limb joint (i.e. the wrist). Clearly, these muscles are not necessary to actively extend and flex the wrist within each wing beat during level flapping (i.e. steady) flight.

Our present understanding of the relationship between musculoskeletal design and flight styles among birds is in its infancy. Biomechanical linkage systems and neuromuscular control of the avian wing have only recently been investigated under experimental conditions. Can anything be deduced about the flight style of a bird solely from inspection of the wing skeletal elements? Consider the forelimb skeletal elements of five different species of birds (Fig. 7). The degree of stoutness of the ulna and radius, and the amount of lateral bowing of these two bones provide an indicator of the relative muscle mass attached to these structures. Inspection of these elements alone may be sufficient to interpret something meaningful 


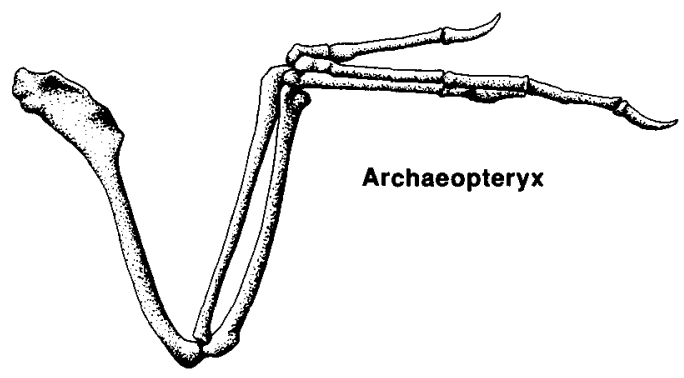

Fig. 8. Skeletal elements of forelimb in Archaeopteryx lithographica. Note simple articular surfaces of ulna-radius complex with carpometacarpus, and also the absence of bowing between ulna and radius. Illustration drawn from photograph taken of Berlin specimen housed in Humbolt Museum fur Naturkunde.

about the flight styles and capabilities of the species in question. For example, birds that perform a substantial amount of nonsteady flight (e.g. hummingbirds, pigeons, and gallinaceous birds) possess stout skeletal forearm elements and, additionally, the ulna and radius bow away from one another. These conditions are indicative of species with substantial forearm musculature. Hummingbirds hover while foraging, while pigeons exhibit near vertical takeoffs and descents from clifflike structures. Galliforms are primarily terrestrial and employ short-distance maneuverable flights when disturbed. In contrast, species that perform predominately steady flight, such as long-distance shorebird migrants and pelagic species (e.g. large procellariiforms), have forearm skeletal elements that are slender and lack pronounced bowing or separation between the ulna and radius (this condition is particularly obvious in albatrosses; Fig. 7). Albatrosses are sometimes referred to as "gooney birds" because of the lack of finesse they display during takeoffs and landings (in addition to their comical courtship behavior). These birds are unable to change significantly the shape of their wings during nonsteady flight and, therefore, look uncoordinated during takeoffs and landings. Albatrosses perform dynamic soaring at moderate to high velocities. They change the shape of their outstretched wings primarily during gliding and, therefore, possess minimal musculature within their forelimbs.

Most bird species possess forelimbs with a moderate degree of ulna-radial bowing, and these skeletal elements are of conservative girth (e.g. European Starling, Sturnus vulgaris; Fig. 7).
The forelimb musculature of passerines typically falls between the characteristics of hummingbird and albatross forelimbs. Future studies should investigate the functional relationship between muscle architecture, skeletal forelimb characteristics, and flight styles.

Comparing closely related taxa that exhibit different flight habits may provide insight into the relationship between form and function of the musculoskeletal system within the wing. Hummingbirds are capable of sophisticated nonsteady flight. Their ability to change body position in a fixed location, such as at a flower during feeding, and their maneuverability in dense vegetation is unparalleled among birds. On the other hand, swifts perform an appreciable amount of steady flight while foraging in primarily open habitats. The high degree of radio-ulnar bowing in the hummingbird appears associated with the pronounced development of the pronators and supinators within the antebrachium (unpubl. data). In swifts, the radius and ulna are essentially parallel and exhibit a modest amount of bowing. While swifts possess a robust extensor metacarpi radialis, their pronators and supinators are modest in size, and their radii and ulnae are not robust nor do they bow away from each other as in hummingbirds (unpubl. data).

The flight capability of Archaeopteryx has been, and continues to be, hotly debated (e.g. Hecht et al. 1984). Therefore, it is of considerable interest that the forearm elements of Archaeopter$y x$ do not suggest that these animals possessed a sophisticated linkage system (Fig. 8). Their ulnae and radii did not bow to any appreciable degree, indicating that they probably did not routinely perform nonsteady flight nor prolonged level flapping flight. However, Archaeoptery $x$ may have been a capable glider. Further work on the skeletal reconstruction of the forelimb will be necessary in order to advance our understanding of the flight behavior of Archaeopteryx. In addition, continued work in the area of experimental functional morphology using extant species will provide novel information for a better understanding of the evolution of avian flight.

\section{ACKNOWLEDGMENTS}

L. Becker, C. Bocker, D. Conway, J. Felix, N. Olson, W. Peters, and R. Trenary helped train the birds, assisted in the experimental recordings, and were in- 
volved in various aspects of data analysis. R. Petty assisted in the preparation of Figures 1, 7 and 8. I thank W. Bock, S. Gatesy, R. Hutto, J. Marks, G. Schnell, $B$. Tobalske and two anonymous readers for critically reviewing the paper. The experimental procedures followed the guidelines established by the IACUC for animal care at the Animal Facilities at the University of Montana. This project was supported by the National Science Foundation Grant BNS-89-08243.

\section{Literature Cited}

Bock, W. J. 1974. The avian skeletomuscular system. Pages 120-257 in Avian biology, vol. IV (D. S Farner, J. R. King, and K. Parkes, Eds.). Academic Press, New York.

BReAZILE, J. E., AND M. YASUdA. 1979. Systema Nervosum Peripheriale in Nomina Anatomica Avium (J. J. Baumel, A. S. King, A. M. Lucas, J. E. Breazile, and H. E. Evans, Eds.). Academic Press, London

BRown, R. H. J. 1948. The flight of birds. I. The flapping cycle of the pigeon. J. Exp. Biol. 25:322333.

Cavagna, G. A., F. P. SaIbene, AND R. Margaria. 1965 Effect of negative work on the amount of positive work performed by an isolated muscle. J. Appl. Physiol. 20:157-158.

DIAL, K. P. 1992. Activity patterns of the wing muscles of the pigeon (Columba livia) during different modes of flight. J. Exp. Zool. 262:357-373.

Dial, K. P., S. R. Kaplan, G. E. Goslow, JR., AND F. A. JENKINS, JR. 1987. Structure and neural control of the pectoralis in pigeons: Implications for flight mechanics. Anat. Rec. 218:284-287.

Dial, K. P., S. R. Kaplan, G. E. Goslow, JR., and F. A. JENKINS, JR. 1988. A functional analysis of the primary upstroke and downstroke muscles in the domestic pigeon (Columba livia) during flight. J. Exp. Biol. 134:1-16.

Dial, K. P., G. E. Goslow, JR., AND F. A. JenKINS, JR. 1991. The functional anatomy of the shoulder in the European Starling (Sturnus vulgaris). J. Morphol. 207:327-344.

FISHER, H. I. 1946. Adaptations and comparative anatomy of the locomotor apparatus of New World vultures. Am. Midl. Nat. 35:545-727.

FISHER, H. I. 1957. Bony mechanism of automatic flexion and extension in the pigeon's wing. Science 126:446.

GorNIAK, G. C., AND C. GANs. 1980. Quantitative assay of electromyograms during mastication in domestic cats (Felis catus). J. Morphol. 163:253281.

Headley, F. W. 1895. Structure and life of birds. Macmillan, London.

Hecht, M. K., J. H. Ostrom, G. Viohl, and P. WELLNHOFER, EDS. 1984. The beginnings of birds: Proceedings of the International Archaeopteryx Conference Eichstatt. Bronner and Daentler, Eichstatt.

Hildebrand, M. 1988. Form and function in vertebrate feeding and locomotion. Am. Zool. 28:727738.

IRVING, L., P. F. SCHOLANDER, AND S. W. GRINNELL. 1942. The regulation of arterial blood pressure in the seal during diving. Am. J. Physiol. 135: 557-566.

JENkins, F. A., JR., AND G. E. Goslow, JR. 1983. The functional anatomy of the shoulder of the savannah monitor lizard (Varanus exanthematicus). J. Morph. 175:195-216.

PENNYCUICK, C. J. 1988. Bird flight performance: A practical application manual. Oxford Science Publications, Oxford.

RAIKOW, R. J. 1985. Locomotor system. Pages 57-147 in Form and function in birds, vol. III (A. S. King and J. McLelland, Eds.). Academic Press, London.

RAYNER, J. M. V. 1988. Form and function in avian flight. Curr. Ornithol. 5:1-66.

SAvile, D. B. O. 1957. Adaptive evolution in the avian wing. Evolution 11:212-224.

SCHMIDT-NIELSEN, K. 1984. Scaling: Why is animal size so important? Cambridge Univ. Press, London.

SCHOLANDER, P. F. 1964. Animals in aquatic environments: Diving mammals and birds. Pages 729741 in Handbook of physiology, Sec. 4, Adaptation to the environment, 2nd ed. (D. B. Dill, Ed.). American Physiological Society, Washington, D.C.

ShafFer, B., AND G. V. LAUdER. 1985. Aquatic prey capture in ambystomatid salamanders: Patterns of variation in muscle activity. J. Morphol. 183: 273-284.

SPEDDING, G. R. 1987. The wake of a Kestrel (Falco tinnunculus) in flapping flight. J. Exp. Biol. 127: 59-78.

SY, M.-H. 1936. Funktionell-anatomische Untersuchungen am Vogelflugel. J. Orn. Lpz. 84:199296.

TUCKER, V. A. 1968. Respiratory exchange and evaporative water loss in the flying Budgerigar. J. Exp. Biol. 48:67-87. 